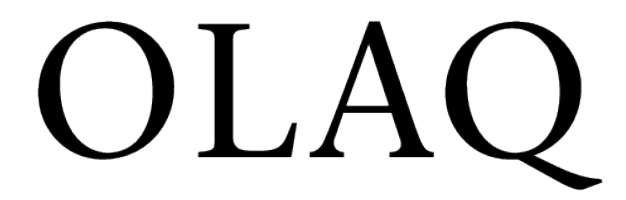

Volume 23 , Number 1 OLA Today: Oregon Librarians Respond to Changing Times | Pages 13 - 15

$8-1-2017$

Fake News and Information Literacy: Creating Resources to Develop Source Evaluation Skills at the University of Oregon Libraries

Carolina Hernandez

University of Oregon

Follow this and additional works at: https://commons.pacificu.edu/olaq

Part of the Communication Technology and New Media Commons, Education Commons,

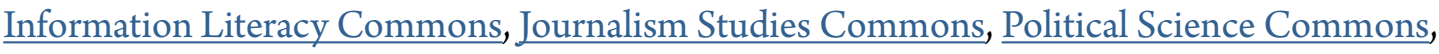
$\underline{\text { Scholarly Communication Commons, and the Scholarly Publishing Commons }}$

Hernandez, C. (2017). Fake News and Information Literacy: Creating Resources to Develop Source Evaluation Skills at the University of Oregon Libraries. OLA Quarterly, 23(1), 13-15. https://doi.org/10.7710/1093-7374.1885

(C) 2017 by the author(s).

OLA Quarterly is an official publication of the Oregon Library Association | ISSN 1093-7374 | http://commons.pacificu.edu/olaq 


\section{Fake News and Information Literacy: Creating Resources to Develop Source Evaluation Skills at the University of Oregon Libraries}

\author{
by Carolina Hernandez \\ Journalism and \\ Communication Librarian, \\ University of Oregon Libraries \\ cahernan@uoregon.edu \\ @carolina_hrndz
}

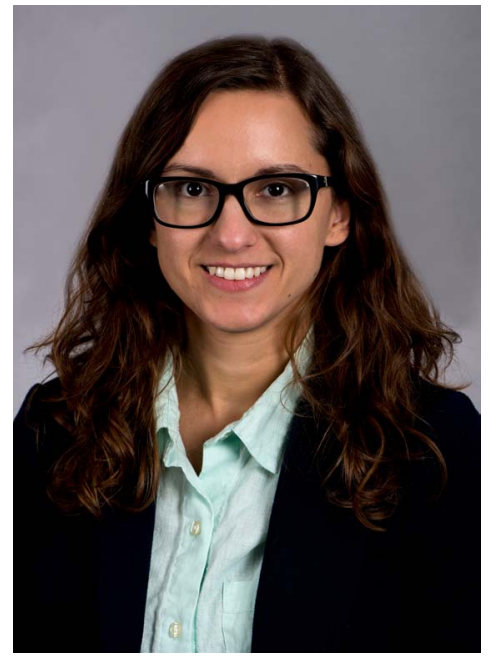

Carolina Hernandez

Carolina is currently the Journalism and Communication Librarian at the University of Oregon Libraries. Her current research interests involve innovative approaches to outreach and diversity-related issues in academic libraries. She received her MLIS from the University of Wisconsin-Madison and an MA in Media Studies from the University of Texas at Austin.
In the months following the 2016 presidential election, much discussion has occurred regarding the proliferation of "fake news" and what impact it may have had on the election results. Regardless of whether there was an actual increase in fake news in the last year, it is certainly true that interest in the topic has increased dramatically. Interest appeared to peak in January, according to Google Trends (Google Trends, n.d.). Widespread concern over how to prevent the spread of this problem has lead to possible solutions cropping up often.

Though often excluded from these recommendations, libraries have the opportunity to play a natural role in combating this problem. Librarians have always understood the need for source evaluation skills in determining credibility, and indeed, many libraries across the country have created resources for others to strengthen and cultivate these skills. At the University of Oregon (UO) Libraries, the response has been no different. With clear interest across campus in having the right tools to counteract the effects of fake news, we decided that we needed to create our own research guide (Hernandez, 2017). As the Journalism and Communication Librarian, I was in a natural position to compile the relevant resources, which eventually led to the development of an instructional exercise. As interest and need continued, the exercise became the basis for a future workshop on evaluating news sources.

Before reviewing the details of building the guide and exercise, I will address the decision to focus on fake news in particular. In researching other fake news research guides that already existed, a trend emerged: these guides tended toward focusing on tools and checklists for evaluating a news source. I wanted the UO guide to show more than just how to identify and avoid fake news. It was also important to:

- Draw a connection between developing evaluative skills in relation to fake news and translating these skills towards assessing other types of information.

- Work towards increasing information literacy more broadly.

- Create an opportunity to highlight a topical issue and use it as an access point to other tools and resources. 
How did I do this? First, I divided the guide into four distinct sections, thereby allowing the focus to flow from fake news to a broader use of information literacy skills. Knowing that the concept of information literacy would be new to some, at least under that terminology, the first section of the guide introduced this topic and provided the connection to fake news and beyond. It was critical that potential users did not feel alienated by the concept or jargon and understood the connection from the start.

I also looked into the resources other libraries had created, since it was not necessary to reinvent the wheel. This initial step yielded a list of some excellent websites, apps, and software that can be used in detecting fake news, which formed the basis for the second section of the guide. I also gleaned resources from some of my colleagues in the School of Journalism and Communication (SOJC) at $\mathrm{UO}$ to include on this page of the guide. These resources were more practical and provided users with tools to address a very specific issue within the information landscape.

The third section went beyond tools specifically for fake news and focused on improving skills related to information literacy. This section highlighted other issues affecting perception and evaluation of the media: i.e., bias, among others. It also provided information on organizations and online courses that provide self-guided resources. This led nicely into the fourth and final section of the guide, which included a set of tables that present key aspects for evaluating the credibility of a source, regardless of information type. The evaluation tables provide a framework of questions to ask when assessing the authority, objectivity, quality, currency, and relevancy of a source.

Upon completion, the research guide was well received in the UO community, becoming one of our most popular guides in the months since it was introduced. Part of its success was due to the work of our Communications and Marketing Department, who were very invested in promoting the guide through the library's homepage and social media accounts. In addition, a feature story was shared through Around the $O$, a hub for news about the UO community. The latter in particular helped to draw attention from a broader audience across campus and generate feedback from faculty in a variety of disciplines from business to dance.

After the successful launch of the guide, I considered other resources we could offer students and faculty. After discussions with SOJC colleagues, we agreed it would be useful to produce an interactive workshop on news and information literacy. Though this workshop is still in development, I have designed an instructional exercise that may form the workshop's foundation. With help from colleagues, I created an activity that introduces students to the "Fake News and Information Literacy" guide and has them work through the process of analyzing different sources. To start this activity, small groups of students receive articles of varying levels of credibility and discussion questions for them to consider during the evaluation of these sources. Using the evaluation tables as a starting point, the students read through the articles, then decide which sources are credible and which are biased or "fake." As part of the exercise, they would also consider and discuss how they might use the different types of sources. Because of the different environments in which we often teach, I wanted to make sure this would be an adaptable activity that could be presented digitally or in an analog setting with printed hard copies. For a session in a computer-less classroom, a librarian could prepare a packet with the articles printed out, as well as any necessary contextual information that would assist in evaluating each source. In a digital context, the set-up could be more fluid, with students discovering contextual information themselves. 
While interest in fake news may wane over time, the ability to evaluate a variety of sources accurately and effectively will always be necessary. Because critical thinking skills are timeless, it is important to emphasize, particularly to students, that it is not only valuable to learn how to identify fake news, but that it is also essential to know how to discern the credibility of any type of source. By framing the concept of information literacy within current concerns of fake news, I generated a resource that resonated with users across campus and across disciplines.

\section{References}

Explore search interest for fake news by time, location and popularity on Google Trends. (n.d.). Retrieved July 09, 2017, from

https://trends.google.com/trends/explore?q=fake\%20news

Hernandez, C. (2017). Fake News and Information Literacy. Retrieved from http://researchguides.uoregon.edu/fakenews.

Stone, J. (2017, February 24). Library guide, SOJC offer tools and tips to combat fake news. Around the $O$. Retrieved from

https://around.uoregon.edu/content/library-fake-news-guide.

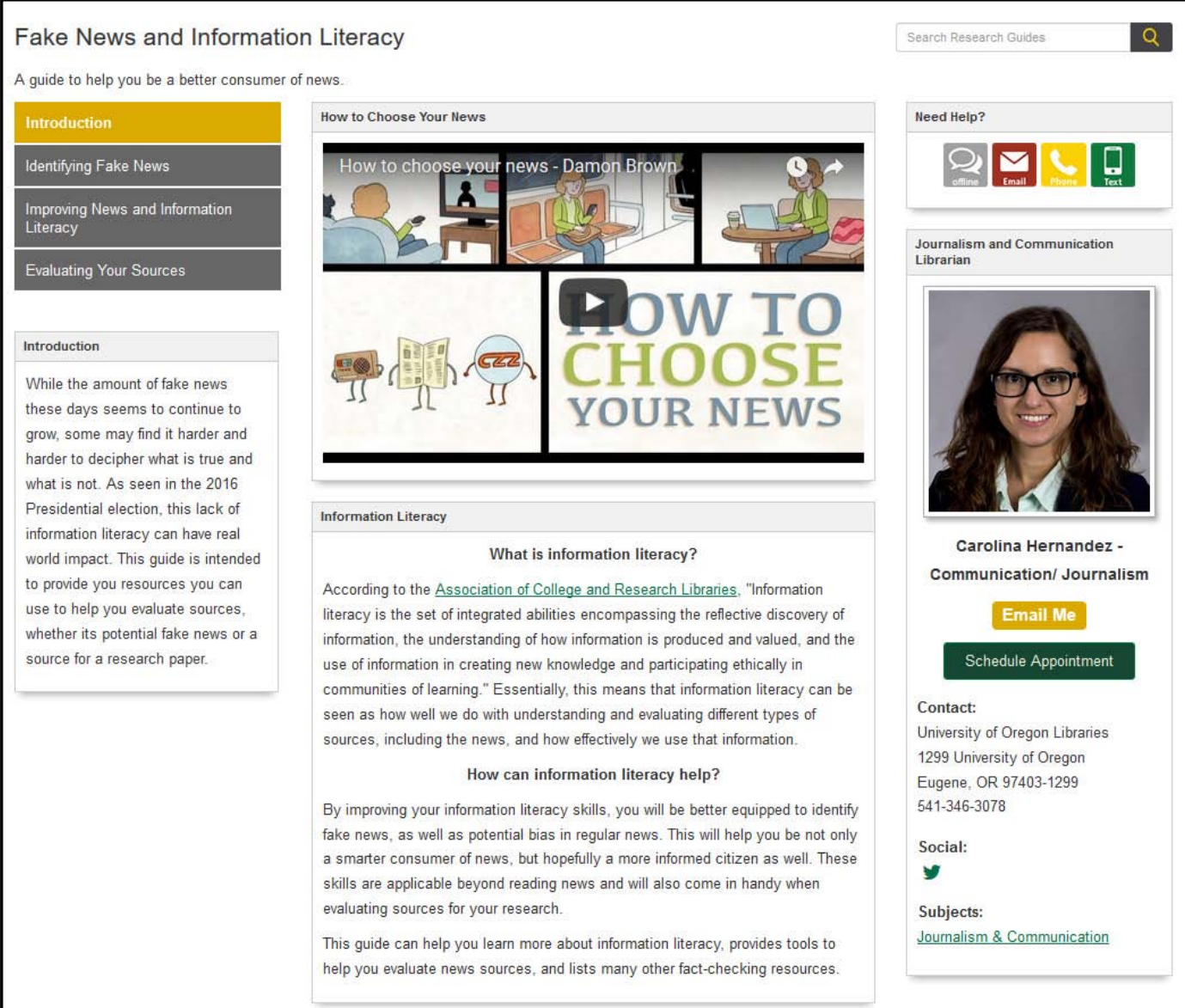

